\title{
Electronic Mentoring in the Digital Age: The Role of Social Media as a "Game Changer" In Mentoring Practices within Higher Education
}

\author{
Dr. Runash Ramhurry \\ University of Johannesburg (UJ), South Africa
}

\begin{abstract}
This paper problematises novice lecturers' experiences in integrating themselves into University life against a background of challenging new developments in the South African Higher Education sector. The primary aim of the study was to investigate their experiences and perceptions of mentoring practices and how it contributed to their social learning in a university context. The study was framed by two theories, firstly, mentoring theory- particularly the work of Kram (1984) and Lave and Wenger's (2002) model of Social learning. To determine the academics' conceptions of mentoring experiences or the lack thereof, the study adopted an interpretivist paradigm, using discourse-oriented interviews, to solicit data from 20 purposively sampled newly appointed academic staff in the first two years of their academic careers- at a South African university. Data was coded, analysed into categories and finally three themes emerged from the transcribed and coded data. The most significant theme to emerge from the data analysis revealed that the neophyte appropriated electronic mentoring platforms- of which WhatsApp and YouTube featured prominently. Resultingly, neophytes enhanced their social learning and successfully assimilated into the academe. The study recommends broader, intensive, institutional discussion of conceptual issues around electronic mentoring and its benefits for both the institution and the novice lecturer. Indeed, the use of social media platforms offers a window of what 4IR tools could offer and arguably, it is a crucial "gamechanger" by taking traditional mentoring as we know it, into the digital age.
\end{abstract}

Keywords: Electronic mentoring; informal learning; mentoring; neophytes; Virtual communities of practice 


\section{Introduction}

This paper problematises novice lecturers' experiences in integrating themselves into University life against a background of challenging circumstances. Novice lecturers for the purposes of this study, are newly qualified lecturers in their first two years in their academic career. Recent developments around the HE sectors in South Africa have presented a multiplicity of challenges for novice lecturers. Some of the well-documented systemic challenges include reduced financial support from Government for both institutions and students; the burden of (ever-increasing) tuition fees; increased workloads for staff with the attendant demand for research output; a move towards mass higher education; advances in technology; and a perceived deterioration in aspects of collegiality in academic life (Hodkinson $\&$ Taylor 2002). To add to the current milieu, the Covid-19 pandemic, and the demands to embrace 4IR has conflated to create new and unprecedented challenges to the academe affecting both staff and students (Hedding, Greve, Breetzke, Nel, \& Van Vuuren, 2020).

Against this challenging background, the plight of the novice lecturer in South Africa has not drawn significant research attention. Novices, being new to the field, face the challenge of having to learn and adjust to the extensive lists of rules and administrative processes of new institutions (Guilfoyle 1995; Guilfoyle, Hamilton, Pinnegar, \& Placier 1996). New lecturers may be overwhelmed with additional work during their induction period (Boyd \& Harris, 2010), such as teaching and administrative roles at the university or consulting with other schools within the university. Moreover, they are required to be independent, creative and selfmanaged (Martinez, 2013). Such pressures are argued to lead to a sense of isolation (Knowles \& Cole, 1994; Guilfoyle, Hamilton, Pinnegar, \& Placier 1996). It is well - documented that novices' feelings of isolation and loneliness (Cawyer \& Friedrich, 1998), high stress levels (Savage, Karp \& Logue, 2004, 21), low satisfaction, and a lack of role definition (Olsen 1993) have serious consequences for their well being and professional development. Indeed, one may 
characterise the socialising process into the academe as challenging (Gourlay 2011; Schrodt, Cawyer \& Sanders 2003).

To address these problems, in the past, debates around the plight of the novice lecturer argue for formal mentorship as a way forward, and educational developers maintained a primary focus on the newcomer as an individual. It was seen as an optimum approach to clarify expectations in terms of professional conduct and performance (Selby \& Calhoun cited in Lucas \& Murray 2002, 26).

By contrast, more recent endeavours have attempted to move the focus away from the novice as an individual in the learning process to that of being a social learner (Hodkinson \& Hodkinson 2004). The growing influence of Vygotsky's (1978) theory of social constructivism points to a move away from an individualistic focus, to one that recognises the contribution of others to every individual's learning. In short, a movement from the "Age of the Individual to the Era of Community" (Feldman 2000, xiii). Research has thus augmented this new direction by moving the focus from how individuals learn by themselves to social learning. To understand such social learning, two theories were deemed appropriate to underpin this study; Mentoring theory, as propounded by Kram (1974) and Communities of practice (Lave and Wenger, 1991). These theories give good purchase to the notion that neophytes find it easier, albeit mediated in informal arrangements, learning from their interaction with their peers (Jennings \& Wargnier, 2011). Put in another way, faculty need to learn from colleagues to help them to apply knowledge in practice (Knight et al., 2006).

In this vein, research goes as far to suggest that a broader, more flexible network of support, in which no single person is expected to possess the expertise required helping someone, be used to navigate the shoals of a faculty career. This relationship is underpinned by an informal unstructured and almost invisible process of peer professional support called mentoring - a process where a person (a mentor) offers help, guidance, advise (counsels) and support to 
facilitate the learning and (professional) development of another person (mentee or protégée) (Aladejana, Aladejana \& Ehindero 2006).

In this model, early-career faculties (novices/neophytes) build robust networks by engaging multiple "mentoring partners" in non-hierarchical, collaborative, cross-cultural partnerships (and informal relationships) to address specific areas of faculty activity, such as research, teaching, working towards tenure, and striking a balance between work and life (Sorcinelli \& Yun 2007, 1). This gives credence to the view that the isolation and related negative experiences of new lecturers can be reduced by making connections with more experienced and knowledgeable peers who have the capacity to guide and facilitate them into academic life - in other words, via social learning. Hodkinson and Hodkinson 2004a, 21, in (Warhurst 2008, 453), support the argument that lecturers' appropriate informal or incidental encounters with colleagues- are crucial for developing as academics (Warhurst 2008, 453). It would seem that these encounters are now expanded into the digital age with the widespread use of social media platforms- ranging from WhatsApp, YouTube, TedTalks and the like. With the introduction of Web 2.0 technology, web platforms have become more dynamic, and this has led to the growth of virtual communities of practice (VCoP) (Jokisalo \& Riu, 2009; Gülbahar, 2014; Susilo, 2014). However, this technology is not free from criticism. Despite fears that virtual arrangements due to its very nature may lead to a lack of engagement (because of a reluctance to share and fear of criticism) and consequently, may lead to a weakened sense of community (Ardichvili, Page \& Wetling, 2003), there is also evidence that virtual communities of practice (VCoPs) with a clear structure and institutional support offer extensive opportunities for faculty development (Sherer, Shea \& Kristensen, 2003).

In this vein, e-mentoring can be employed to assist in the socialising of newcomers to the academe and is seen as a viable alternative to conventional forms of mentoring and gives credence to the ideas that, "the use of computer-mediated communications such as e-mail, discussion boards, chat rooms, blogs, Web conferencing, and growing Internet-based solutions that are changing the way mentors and mentees interact" Smith and Israel (2010: 30). The end 
goal of virtual or e -mentoring is to replicate best practices of traditional mentoring but mediated in a digital space, with academics thriving and finding compensation for the absence of a "physical co-presence" and the privacy required for "conversations about sensitive issues" (Pachler \& Redondo, 2012: 469, in Mullen, 2016: 113). It is cogent here to define E-mentoring. "E-mentoring refers to a relationship in which a mentor, usually a more experienced or an older person, provides guidance and support to a less experienced or younger person (the mentee) via distance communication technologies" (Shpigelman 2014, 259). Primarily, ementoring refers to text-based electronic communication (Single \& Single 2005). Most ementoring programs have been based on asynchronous communication, which is communication that is not dependent on the physical presence of the users. In this informal arrangement, each user can send messages or reply to others at different times (Harris \& Figg 2000 in Shpigelman 2014, 260). With developing technology, like WhatsApp, e-mentoring, respectively, have expanded to include multimedia and synchronous communication where the users are present and respond in real time (Shpigelman 2014, 260).

\section{Problem statement and purpose}

The literature argues that informal avenues of learning practices, are a critical, yet neglected, avenue which offer an important contribution to the social learning of novice lecturers (Hodkinson \& Hodkinson 2004, 21; Coffield 2000, 2, in McNally, Blake \& Reid 2009, 323). Indeed, there is a paucity of research on informal mentorship practices, mediated by social media platforms (SMP) and how they contribute to the social learning of novice lecturers as academics in South African university landscape. It is within this knowledge gap, that this paper locates itself, guided by an overarching research question:

How do mentorship practices mediated by social media platforms contribute to the social learning of novice lecturers in a university context? 


\section{Literature Review}

According to Lave and Wenger (1991) who first identified Communities of practice (CoPs) although primarily in an organisational context rather than an academic one, learning does not rest with the individual but is a social process rooted in a cultural and historical context (Farnsworth, Kleanthous, \& Wenger-Trayner, 2016). A community of practice could be seen as 'a community with a joint enterprise, shared repertoire and mutual engagement by its members' (Wenger, 1998: 73).

Overwhelmingly research shows that informal methods are widely adopted amongst faculty (Jennings \& Wargnier, 2011). Colleagues are the supporting structures in the quest for selfimprovement amongst faculty, instead of formal faculty training pro-grammes like induction (FTI Consulting, 2015). A plethora of research indicate that formal workshops alone are unlikely to impact on teaching practice (Saroyan \& Trigwell, 2015). Instead, faculty need to learn from colleagues to help them to apply knowledge in practice (Knight et al., 2006). Hence the establishment of communities of practice (CoPs) provides a valuable opportunity for professional learning independent from formal faculty programmes (Stark \& Smith, 2016).

Similarly, recent literature shows that there has been a shift from the traditional to a more contemporary view of mentoring. In recent times, mentoring is seen as a productive interpersonal process of learning rather than as a role imposed formally from the outside, in which the mentee exercises no power over what happens to him/her. In contrast to the traditional perspective, the mentoring relationship today is largely predicated on equality as both the mentor and mentee are willing to learn from one another as they engage in collaborative partnerships and mutually share knowledge. For example, Faure (2006) advocates the following contemporary view: "Mentoring is a supportive learning relationship between a caring individual who shares knowledge, experience and wisdom with another individual who is ready and willing to benefit from this exchange, to enrich their professional journey". Awaya, McEwan, Heyler, Linsky, Lum, \& Wakukawa (2003) emphasise that 
mentoring is a collaborative partnership between two individuals based on care and friendship, and one in which both parties enjoy equal status. However, e-mentoring has now taken precedence and will, arguably, supplant traditional forms of mentoring, especially in the face of present circumstances dictated by Covid-19. Mentorship during the coronavirus pandemic has been greatly altered (Nocco, McGill, MacKenzie, Tonietto, Dudney, Bletz, \& Kuebbing, 2021).

\section{A Case for Virtual or E-mentoring:}

Strikingly similar to face-to-face mentoring, e-mentoring or virtual mentoring, involves two or more people working in a mentoring relationship albeit at times, separated geographically (Owen, 2014). E-mentoring arguably, opens the door for greater flexibility in creating and sustaining relationships. For instance, since mentors are not limited to specific regional locations, more individuals can participate as mentors. Additionally, the reduced level of social cues over electronic media may allow greater opportunities for women and minorities to interact with mentors (Hamilton \& Scandura (2003: 389).

Further, virtual mentoring coheres for other reasons as well. Face-to-face interactions may be distracted by visual cues, and issues related to setting, context, and atmosphere may hamper communication. E-mail and text-based messaging are leaner communication channels that allow for more direct information transfer- thus minimizing contextual issues (Hamilton \& Scandura (2003: 389). Virtual mentoring may also help overcome time constraints and busy work schedules and may help to maintain sustainable mentorship practices in the long run. Further, the convenience offered by e-mentoring opens the opportunity to all in accessing a larger, more diverse range of mentors than might be readily available at work. It is furthered argued that current trends in technology, which include rich multimedia communication in real time, enable emotional expression and social bonding that one typically observes in face-toface interactions (Hamilton \& Scandura (2003: 389). 
One such social media platform that offers a sense of bonding, albeit virtually, is WhatsApp. Since its first release in 2010, WhatsApp developers have incorporated additional features to it that makes it suitable for supporting communication in teaching and learning (Bouhnik, \& Deshen 2014). In their study, Boyinbode, Agbonifo, \& Ogundare (2017) conclude that WhatsApp application could greatly support learning activities. Similarly, Yavuz (2016) recommends that collaborative study groups should be formed to motivate learners and raise achievements of all.

The end goal of virtual or e -mentoring is to replicate best practices of traditional mentoring but mediated in a digital space, with academics thriving and finding compensation for the absence of a "physical co-presence" and the privacy required for "conversations about sensitive issues" (Pachler \& Redondo, 2012: 469, in Mullen, 2016: 113). Presently, mentors and mentees as just too busy due to work schedules, and/or social distancing due to Covid-19), could lead the way in the formation of virtual communities of practice (vCoP) (Stewart, 2010). These virtual communities of practice offer opportunities for the interaction and sharing of information between expert and novices and amongst newcomers themselves. In a vCoP, opportunities also abound for reverse mentoring where the novices' mentor their more experienced colleagues and in the process, are re-tooled and rejuvenated (Murphy, 2012). In fact, VCoPs can be viewed as an innovative method for faculty development through collaborative learning and enhancement of a sense of community for all (Yang, O'Reilly \& Houghton, 2020). A VCoP uses social media to support online community interaction and collaborative learning (Malecela, 2016). With the growth of social media, real-time communication and collaboration within a community is now a reality (Amry, 2014).

The popularity of WhatsApp is multifold, inter alia- the ability to allow for an almost fluent conversation; creating a sense of belongings; low cost; its accessibility, and ease of use for communication purposes (Church, \& de Oliveira, 2013). Further, the versatility of WhatsApp lies in its ability to create groups and then allows the sharing of text messages, chats, images, audio, video, and web links within the group (Bouhnik \& Deshen, 2014; Sayan, 2016). The use 
of WhatsApp seems to complement Social constructivist learning theory, which underlined the importance of social interactions rather than observation Vygotsky (1978). Smart Phones makes this possible as it allows for learning to occur anywhere and anytime (Crescente \& Lee 2011). WhatsApp is smartphone application that allows for instant message sending to either an individuals or groups. Pictures, audio-visual files attachment and websites links can be sent through it. It also allows for files sharing (Ujakpa, Heukelman, Lazarus, Neiss, \& Rukanda 2018). Indeed, the use of WhatsApp allows for academic information sharing through conversations between and among novice lecturers.

In a digital world, where ubiquitous computing and demand-driven learning are the norm, it is crucial for all members to become active participants and co-producers of content and learning processes, rather than mere recipients (McLoughlin \& Lee, 2008). In higher education, mentorship (in its traditional and modern-day variant, e-mentoring) can upsurge research funding and publication rates (Darwin and Palmer, 2009), and aid in promotion prospects peers (Koontz, Walters, \& Edkin, 2019). Today, Higher education is progressively competitive, often based on earning significant research revenue and a mindset of publishing early and frequently (Chandler, 1996; Darwin \& Palmer, 2009; de Janasz and Sullivan, 2004; Lipton, 2017; Meschitti and Lawton Smith, 2017). This impetus is witnessed in many alternate mentoring enterprises, including mentoring circles (Darwin \& Palmer, 2009), collective mentoring (Chesler \& Chesler, 2002), group mentoring (Huizing, 2012) and strategic collaboration (Wasburn, 2007, in Koontz, Walters, \& Edkin, 2019) and now e-mentoring, especially via WhatsApp (Ujakpa,et al, 2018).

The challenges with the execution of mentoring programs that necessitate the configuration of pairing mentor partners are well-documented. However, “...not everyone is a competent mentor and arranged relationships are not always ideal" (Darwin and Palmer, 2009:126). Some like, de Janasz, Sullivan, \& Whiting, (2003) claim that traditional mentoring programs have the limitation of restricting novices to a single person's viewpoint. E- mentoring with its ability to connect to a wider range of mentors offers ways to overcome such arrangements. While 
many studies explore the potential of face-to-face mentoring and professional learning communities (Kidd and Murray 2013), there are fewer studies that investigate the effects in a virtual environment, especially in the South African milieu. Furthermore, a younger replica of oneself is the guiding principle behind the motivation when it comes to selecting a mentee (Erikson, 1963; Meschitti \& Lawton Smith, 2017). However, this could be an abomination to women and women of colour since academia has conventionally been a white male space (Meschitti \& Lawton Smith, 2017).

A solution could be offered by e- mentoring. Indeed, e-mentoring is considered an opportune and a convenient means of mediating communication since it overcomes the barrier of faceto- face mentoring by obviating that need, as it is not bound by time nor place (Watson, 2006; Harrington, 1999). As such, e-mentoring provides flexible scheduling to meet the needs of both parties. Further, e- mentoring makes allowance for a neutral, third-party viewpoint because both parties are conscious of the fact that they may not ever meet in person (Harrington, 1999). However, there are caveats: some researchers believe that e-mentoring may also have weaknesses because electronic mediation could be seen as impersonal, ambiguous and unsuitable for communication. However, other researchers contend that it is workable, and its use and development is predicated largely on trust- a prerequisite for its success (Premkumar \& Wong, 2010).

Indeed, to be successful in academia, multiple mentors are required as propounded by Darwin and Palmer (2009). However, this represents the ideal; multiple mentors are not always available, and, in this gap, e-mentoring (or electronic mentoring) provides an alternate solution. Not unlike traditional face-to-face variation of mentorship practices, online mentoring also aims to contribute to academics' professional growth primarily mediated by computermediated communication tools (Cinkara \& Arslan, 2017:40).

E-mentoring offers new pathways to traditional forms of mentoring. Further, it is common knowledge that teaching contexts within the academe vary quite considerably; individuals may 
develop different kinds of learning, teaching and mentoring relationships(ibid), depending on such variables as faculty-specific knowledge areas, staff numbers and scope and depth of its resources. The internet has advanced and rapidly influenced every sphere of life including mentoring (Single \& Single, 2005).

In this vein, e-mentoring can be employed to assist in the socialising of newcomers to the academe and is seen as a viable choice to conventional forms of mentoring and gives credence to the ideas that, "the use of computer-mediated communications such as e-mail, discussion boards, chat rooms, blogs, Web conferencing, and growing Internet-based solutions that are changing the way mentors and mentees interact” Smith and Israel (2010: 30).

Since e-mentoring is time and place independent, it might be helpful for busy newcomers to have contact with a large cohort of contemporaries teaching similar or related research niches. As noted earlier, mentoring, is mediated via email and synchronous chats via WhatsApp, and via diverse social media online platforms and calling technologies (Mullen, 2016). In this context, the exchange of ideas by novice lecturers on WhatsApp, could be addressed within the context of communities of practice. Indeed, WhatsApp has become a significant alternative for learning and teaching (Cansoy, 2017).

It may be argued that the benefits of mentoring in an informal e- mentoring platform such as WhatsApp, has the potential of elevating the reputation and profile of the mentor as well. Indeed, informal mentoring relationships mediated by WhatsApp, is by virtue, not obligatory and hence, free from overt pressure of traditional mentoring dyads. Further, the stress-free atmosphere shaped by informal mentoring, fosters even more psychosocial and professional support than required (Darwin \& Palmer, 2009). All these ideas coalesce around Kram (1996) ideas of "connectedness" but much more than she could have ever envisioned- the connectedness offered by social media, particularly so by WhatsApp. Kram defined "personal learning" as the attaining of knowledge, skills, or competencies which mediates individual development- inclusive of interpersonal proficiencies of “.... self-reflection, self-disclosure, 
active listening, empathy, and feedback". These attributes resonate the much-vaunted notion of greater awareness of oneself "as increasingly connected to others" (Kram, 1996: 140). WhatsApp embraces these ideas and offers a novel way of connecting academics as opposed to conventional mentoring relationships.

\section{Conceptual Framework}

A conceptual framework helps guide the analysis of collected data, which supports knowledge generation and an understanding of the concept or concepts under study (Ndlovu \& Hanekom, 2014) or as 'the current version of the researcher's map of the territory being investigated' Miles and Huberman (1984: 33). For this study, virtual or e- mentoring particularly the use of WhatsApp by novice lecturers was not part of the study design but arose as a support adjunct of the study. The study was framed by two theories. Firstly, Social Constructivism theory, particularly of that of Vygotsky (1978), was used as a broad framework to scaffold mentoring theory. Secondly, the study employed Lave and Wenger's (2002) model of learning, which argues that learning involves a process of engagement in a 'community of practice' (CoP) (ibid, 115). This study was conducted within the interpretivist paradigm of social inquiry (Alvesson \& Sköldberg 2000; Holliday 2001), with the aim of coming to some understanding of novice lecturers' experiences of mentorship practices in their first year(s) of teaching.

Mentoring theory, as propounded by (Kram, 1985), outlined the important role of a more experienced person (an experienced lecturer) who serves as a mentor to a novice (lecturer) by offering career-related and psychosocial support. However, mentoring relationship at a university could also be seen as supporting novice lecturers to "manage their own learning in order to maximize their professional potential, develop their skills, improve their performance, and become the person they want to be" (Parsloe, 1992).

Situated Learning Theory developed from the theories of Lave and Wenger (1991) and Wenger (1998). This theory provides an ideal backdrop to examine the social appropriation of learning at the university. Lave and Wenger (1990), arguing from a constructivist view of learning and 
development, have posited the theory of legitimate peripheral participation (LPP) as a form of learning in a community. According to this theory, people learn when they become an "insider" within a community. Once inside they adopt or take on the language and viewpoints of that particular group. Thus, a novice lecturer learns to become an academic by adopting the prevailing symbols and actions commonly accepted by other lecturers. The absence of such support structures, vis- $a$ vis a community, makes it difficult for the novice to learn to cope with learning.

\section{Participants}

To suit the purposes of my study, the participants were selected by means of purposive sampling, which enables the researcher "...to identify and target individuals who are 'typical' of the population being studied..." (Davies, 2007: 57). This view is corroborated by Creswell (2002: 194), who states that in purposive sampling the participants are selected deliberately so that the main phenomenon can be understood. Following the ideas of (Creswell, 2002), use was made of a purposive sampling strategy to select a group of twenty novice lecturers to participate in this study, either to avail themselves to an interview or to complete a survey by means of a questionnaire which was emailed to them.

\section{Data Collation}

The primary source of data elicited from the participants were discursive oriented interviews. Novice lecturers were interviewed to investigate how mentoring practices (or a lack thereof), contributes to their learning as academics. The narratives that emerge from their responses will be analysed and themes relating to their development as academics will be drawn out. The secondary sources of data collection included a mentoring survey in the form of a questionnaire- for those participants who could not avail themselves to an interview and document analysis of internal documents from the university which helped to corroborate the data from the interviews. Following the ideas of (Creswell 2002), a purposive sampling strategy was adopted to select a group of twenty novice lecturers to participate in this study. In 
this study I based my research within one particular university, with participants from three campuses. These novices were selected from the various faculties/departments, all having a fresh intake of novice lecturers.

\section{Research methodology}

The study adopted a qualitative research design because it aligned well to the goals of this inquiry: a qualitative strategy is underpinned by a constructivist philosophy, which sees reality as a multiple layered, interactive social construction (Merriam 1998). For the purposes of this study, such a strategy facilitated a deep analysis of the novice lecturers' social lifeworlds. Although in-depth involvement was facilitated, as a qualitative researcher, due cognizance and awareness of becoming overly engaged in the phenomena under investigation (Henning, Van Rensburg and Smit, 2004); (Cole 1996) were observed. Following the advice of McMillan and Schumacher (2001, 411), the researcher adopted a stance of disciplined subjectivity which involved our "self-questioning and use of personal experimental empathy in data collection". This translated to developing trust, being non-judgmental and showing sensitivity regarding issues of an ethical nature. 


\section{Data Analysis}

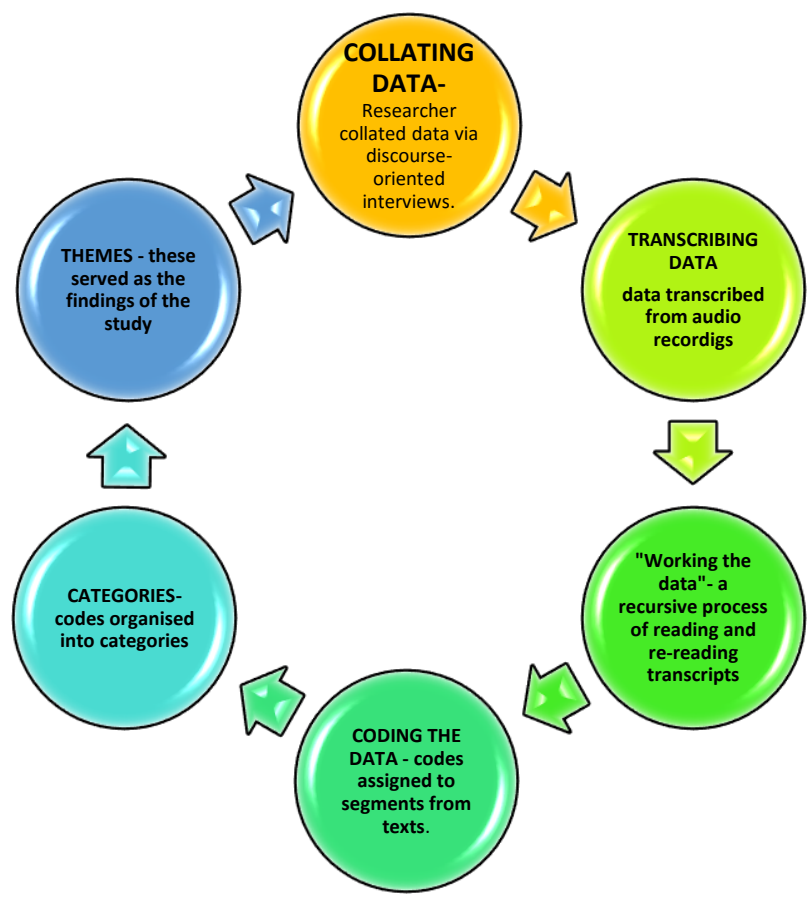

\section{A Recursive process that occurred simultaneously}

Figure 1: The qualitative process of data analysis (adapted from Creswell, 2002; 2017 and Henning et al. 2004)

In order to gain in-depth understanding of novice lecturers' perceptions and meanings, data was collected via individual face-to-face discursive oriented interviews. Participants were selected by means of purposive sampling, which enabled the researcher "...to identify and target individuals" who were 'typical' of the population being studied..." (Davies 2007, 57). Following the ideas of Creswell (2002), a group of twenty novice lecturers were intentionally 
selected so that different faculties, departments and campuses, which made up the university population, were represented.

Discourse Analysis in conjunction with thematic analysis was adopted as the key analytical tool because its underpinning principles gelled strongly with the theoretical framework of this study. Discourse analysis was seen as a favorable tool because it emphasizes the role of language in the construction of social reality, making visible the perspectives and starting points on the basis of which knowledge and meanings are produced in a particular historical moment (Talja, 1999). In line with the aims of this study, it facilitated giving focus to the way in which discourses produce and transform social reality in the social setting of a university environment (Henning et al. 2004). Thematic analysis (TA) involves the process of identifying patterns or themes within qualitative data. Thematic analysis (TA) has been defined as "a method for identifying, analysing and reporting patterns (themes) within data" Boyatzis (1998) cited in Braun and Clark $(2008,79)$. It minimally organizes and describes your data set in (rich) detail. However, frequently it goes further than this, and interprets various aspects of the research topic" (ibid).

Following the ideas of Henning et al. (2004) concerning discourse analysis (DA), the "communicative event" between the researcher and the participants in this study were analysed through a process of coding and categorising semantically related units of the transcribed discursive interviews. The twenty interviews were transcribed as per the suggestions offered by Creswell $(2002,266)$ and (Braun and Clarke 2006). The object of the coding process 
according to Creswell $(2002,266 ; 2012,243)$ is "to make sense of the text data, divide it into text or image segments, label the segments, examine the codes for overlap and redundancy, and collapse these codes into themes" (Fig,1). The researcher also took cognizance of Creswell's (2002) advice and direction that the process involved the act of splitting and labeling text to form broad descriptions and themes in the data. Accordingly, the data from the interviews and questionnaires were analysed using Thematic analysis (TA) and Discourse analysis (DA), which unearthed three themes. The codes of meaning or discourse markers"specific instances of the use of words or phrases that exemplify the discourse" (Henning et al. 2004, 119), were subsequently coalesced into main categories. From these codes of meaning certain discourse themes were then identified. Through this process, themes were continuously refined, thereby gradually moving to higher levels of abstraction, resulting in the construction of broad categories that reflected the focus of the investigation and which serve as the findings (see Fig1).

\section{Findings}

The findings suggested that in the spaces that are given to new academics for the exercise of appropriate pedagogical agency, they were able to develop a sense of self-efficacy and agency with the aid of social media, and in so doing come to successfully assimilate themselves into the academe. 


\section{Self-efficacy mediated by social media.}

The most significant theme emanating from the data analysis process pointedly features the novice lecturer seeking the assistance of social media in the quest to enhance social learning to successfully assimilate into the university. Participants reported a wide array of social media platforms of which, WhatsApp, YouTube, Ted Talks and online Writing Blogs feature prominently. This form of e-mentoring has taken root and is widely used by new faculty to mediate their social learning. Participants viewed social media as a valuable tool to help build informal mentoring relationships (Briones, Janoske \& Paquette 2013, 3).

Regarding communities of practice (Lave \& Wenger 1991) in the more formal sense Wenger (1998) stated that a CoP should consist of people in a shared domain, contain expert-novice interaction and "dense relations of mutual engagement organised around what they are there to do", as well as 'joint enterprise' and a 'shared repertoire' (Wenger 1998). These findings certainly cohere with some of these pre-requisites of a CoP. Reflected in this theme, the CoP did not pre-exit nor were novices encouraged by institutional managers to form one. Perhaps mindful of this Gourlay $(2011,76)$ warns that "... a community should not be assumed to preexist in an academic department in a form that will allow novices with limited experience of advanced scholarship to learn new practices from more experienced colleagues...". Yet, reflecting on the data, it is conspicuous a CoP, albeit on a digital space, primarily by the medium of WhatsApp, a virtual community of practice (vCoP) did manifest itself by the efforts of the novices themselves.

Lenny underscores the importance of using Social media to mediate his social learning by positing: "I explored various .... Searched the internet, ...YouTube for ideas... even got in touch, with colleagues to share ideas on writing, teaching...etcetera... from other departments whom, I met at a random meeting, and created a WhatsApp chat group ... you know things like that... probably every now and again... whenever, I or some colleague needed help with anything...for example, I... I hit a dead wall and just too stressed, when writing papers, I sought 
help from my colleagues". These thoughts illuminate and resonate with extant research. In these online environments, users can create the content, share, and collaborate with other users (Shpigelman 2014, 260).

Similarly, Lenny's thoughts also finds resonance in Jane's musings on her own passage through academia mediated by social media: “...but my biggest platform of learning was my own explorations into YouTube, so YouTube served as the best teacher for me, my best mentor, I learnt a lot from TED Talks where TED Talks air ummmmm experiences of other people mostly in the educational arena about their lives and what they've learnt from true experiences aaaah for example one of the things that I learnt and I hold onto very tightly is... ummm... Concept Mapping! So... there's a powerful presentation on TED Talk on the value of Concept Mapping and how it can help everybody on just about every level of learning. So as a learner, myself, being new to a lecturing, I learnt about Concept Mapping in a different way to the textbook approach that I had when I was a student. So... YouTube for me, WhatsApp for me, e-mail and TED Talks became the big... best platform of learning for me" (T/Ja:3). It would then suggest that Jane has a vested predilection for e-mentoring programs have been based on asynchronous communication, which is communication that is not dependent on the physical presence of the user (Shpigelman 2014, 260).

Further, she underscores the value of other sources of Social media like YouTube and online Blogs: “... Yes! Into academia, and whenever I found myself in an anxious situation... I looked for a YouTube uuhmmmm similar experience OR I also found blogs that lecturers had written, mostly in international context about how to find your way and I followed these blogs, these teaching blogs, these lecturing $b$ logs from big universities, although many of them are from Ivy-league universities a lot of the ideas were transferrable and I was able to use those ideas like for instance, how to teach a large... a big class. The blogs that people put up of hints and ideas of how to teach are the best way, learning from other people's real- life experiences. Aaahhhh I know that I tried to initiate aaaah the idea of people blogging about their experiences that they could share with others aaaa because blogging is a whole new way for 
us to share our own experiences and it starts... start of in a small scale because I feel that I want to help the next person that comes along and is in my situation" (T/Ja:4). Jane's idea of a shared experience echoes the thoughts of employing social media for faculty development, which may resolve the difficulty many participants encounter in attending face-to-face events, (like induction or staff development opportunities at the university) (Mullen 2016).

Other participants also posit similar meditations. Leonie, reports on the important role WhatsApp played in her social learning by mentioning using this platform of Social media to keep in contact with her informal mentors: "Ahhhh probably once a month, touch base and then on an informal basis via e-mail, WhatsApp and those kind of things..."; whilst Maureen posits: "Sometimes I meet them in their offices, in the corridor or I just phone ... WhatsApp them, aaah very helpful with advice. I must say, using my phone is very convenient way in contacting mentors...quick advice...mmm". With online communities, faculty can join at convenient times from any location and still feel connected (Mullen 2016). As witnessed in this study, WhatsApp application could greatly support learning activities (Boyinbode, Agbonifo, \& Ogundare (2017). Similarly, Yavuz (2016) recommends that collaborative study groups should be formed to motivate learners and raise achievements of all.

These observations resonate with the findings of this study. The popularity of WhatsApp is multifold, inter alia, is its ability to allow for an almost fluent conversation, creating a sense of belongings, low cost, its accessibility and ease of use for communication purposes (Church, \& de Oliveira 2013). The use of WhatsApp seems to complement Social constructivist learning theory, which underlined the importance of social interactions rather than observation Vygotsky (1978). Smart Phones makes this possible as it allows for learning to occur anywhere and anytime (Crescente \& Lee 2011). WhatsApp is smartphone application that allows for instant message sending to either an individuals or groups. Pictures, audio-visual files attachment and websites links can be sent through it. It also allows for files sharing (Ujakpa, Heukelman, Lazarus, Neiss, \& Rukanda 2018). Indeed, the use of WhatsApp allows for 
academic information sharing through conversations between and among novice lecturers and with senior faculty as well.

Several of the participants discussed (by far the majority- 18/20 participants) how they accessed social media platforms (SMP), like blogs, WhatsApp and YouTube, which served as outlets to connect with colleagues or "mentors" in an informal loosely arranged digital/ virtual community of practice ( $\mathrm{VCoP})$. In this digital community, novices offer and receive advice and/or guidance to other neophytes and from other established academics or senior faculty. The use of new Information and Communication Technologies (ICTs) which offer a variety of services are freely available and in some cases are free. The use of social media by novice lecturers at the university seem to align with the vision and precepts of ITC in Higher Education in the twenty-first century with its focus on the development of lifelong learning, more equity of access, quality improvement of teaching methods, diversification of cooperativecollaborative, autonomous learning, and troubleshooting of the physical environment (UNESCO, 1998). WhatsApp allows for academic information sharing through conversations between and among novice lecturers.

Coping strategies and a willingness to take up a challenge feature prominently amongst these novices' experience. These novices were able to adapt and transform themselves, using their experiences of previous employment in other higher institutions or as temporary staff at the university to their benefit. More, significantly perhaps, the data analyses show and underscores the vital role played by social media in the social learning of neophytes. Electronic, online, or digital mentoring, often referred to collectively as e-mentoring, has grown in popularity over recent decades (Mullen 2016), and offer new pathways to understanding the complexities of the socialisation of novice lecturers into the academe. Given the present Covid-19 outbreak and ramifications for personal distancing, vCoP's might yet offer a solution to traditional methods of mentoring. More pointedly, researchers argue that mentorship during the coronavirus pandemic has been greatly altered (Nocco, et al, 2021). 


\section{Conclusion}

The study found that novice lecturers develop as academics through, in the main, via informal learning experiences mediated primarily by social media platforms (SMP)- with a healthy dose of nous and by employing various coping strategies. These included the use of virtual or Ementoring initiatives mediated by various social media platforms (of which, WhatsApp featured most prominently) in a university context. Further, an informal mentoring relationship (in this instance- a virtual space mediated by WhatsApp) emerges from a freely chosen mutual attraction that involves friendship where guidance and nurturing are provided with regard to personal and professional dimensions (Kram 1988; Beres \& Dixon 2014). Informal communities of practice (VCops) could be seen operating at an almost invisible level, in the sense these VCoPs are not formal arrangements, but a coming together of novices and experienced lecturers in a mutual benefitting "arrangement". These experiences may have played a key role in their assimilation into the academe and enabling participation in a community of practice- in this case, a virtual one. In summary, many neophytes embraced technology, making use of various social media platforms to mediate their social learning- of which, WhatsApp, YouTube, TED Talks and online Blogs, feature prominently.

The findings offer insights into how novice lecturers are socialised into the academe. The academe and or the University would do well to encourage such methods of socialisation. Indeed, there is also evidence that virtual communities of practice (VCoPs) with a clear structure and institutional support offer extensive opportunities for faculty development (Sherer, Shea \& Kristensen, 2003).

Stemming from being lost and alone, these neophytes socialised themselves into the academe by either seeking assistance from their more experienced colleagues in a largely informally arranged mentorship in a virtual community of practice (VCoP). These platforms and/ or digital spaces offers new insights into mentoring practices as we know it. One may be argued that the 
neophytes' use of technology breaks new ground in the prevailing and extant discourse of mentorship practices of new academics.

To reiterate, management at the university where the study was conducted need to identify potential communities of practice that will enhance the university's strategic capabilities and visions, provide the infrastructure that will support such communities and enable them to apply their expertise effectively, and use non-traditional methods (like social media platforms) to assess the value of the university's communities of practice (Wenger \& Snyder, 2000: 6). Darwin and Palmer (2009) suggest that to be successful in today's academic environment, one must have access to various mentors, perspectives and insights. While face-to-face mentoring may be seen as optimal or effective (Heirdsfield et al., 2008), the viability of electronic mentoring, or e-mentoring, should be considered. The idea of a shared experience echoes the thoughts of employing social media for faculty development, which may resolve the difficulty many participants encounter in attending face-to-face events, (like induction or staff development opportunities at the university) (Mullen, 2016). Consequently, it is incumbent upon novices and departmental heads that in order to succeed, to make use of a network of multiple intelligent mentors in the face of a constant evolving, fast- changing world affecting the workplace (Darwin \& Palmer, 2009: 126).

The advance of technology and the dawning of the Age of Technology, the Fourth Industrial Revolution (4IR) and the use of the Internet, has witnessed a momentous shift in the manner in which we interact with emerging technologies, including mentoring (Single \& Single, 2005). Mentoring via email, as reflected in the data, “...occurs remotely through email, synchronous chats via WhatsApp, and other social media, and via online platforms and calling technologies" (Mullen, 2016). In this context, the exchange of ideas by novice lecturers on WhatsApp, could be addressed within the context of communities of practice. It can be stated that the WhatsApp application has become a significant alternative for learning and teaching (Cansoy, 2017). More tellingly, research shows that informal methods are widely adopted amongst faculty (Jennings \& Wargnier, 2011). The study concludes that when neophytes actively sought out 
peers and found new ways to socialize themselves into the academe, they took responsibility for their own social learning and basked in the thrill of self-discovery- a learning that can be described as "self-directed" and by appropriating various social media platforms (SMP's), social media offers itself as a "game-changer" in the learning and mentoring of novice lecturers.

\section{References}

Amry, A. B. (2014). The impact of WhatsApp mobile social learning on the achievement and attitudes of female students compared with face- to -face learning in the classroom.

Aladejana, A., Aladejana, F. \& Ehindero, S. (2006). An Analysis of Mentoring Relationships Among Teachers: A Case Study of Obafemi Awolowo University, Ile-Ife, Nigeria. International Journal of Evidence Based Coaching and Mentoring, 4(1):20-32.

Allen, T. D., Eby, L. T., Poteet, M. L., Lentz, E., \& Lima, L. (2004). Career benefits associated with mentoring for protégés: A meta-analysis. Journal of applied psychology, 89(1), 127.

Alvesson, M. \& Sköldberg, K. (2000). Reflexive methodology: New vistas for qualitative research. London: Sage.

Ardichvili, A. Page, V. \& Ventling, T. (2003) Motivation and barriers to participation in virtual knowledge- sharing communities of practice. Journal of Knowledge Management, 7(1), 64-77

Awaya, A., McEwan, H., Heyler, D., Linsky, S., Lum, D., \& Wakukawa, P. (2003). Mentoring as a journey. Teaching and teacher education, 19(1), 45-56.

Bouhnik, D., Deshen, M., \& Gan, R. (2014). WhatsApp goes to school: Mobile instant messaging between teachers and students. Journal of Information Technology Education: Research, 13(1), 217-231. 
Boyd, P., \& Harris, K. (2010). Becoming a university lecturer in teacher education: expert school teachers reconstructing their pedagogy and identity. Professional development in education, 36(1-2), 9-24.

Briones, R., Janoske, M., \& Paquette, M. (2013). New media, new mentoring: An exploration of social media's role in public relations mentorships. PRism 9(1):

http://www.prismjournal.org/homepage.html. Accessed 15 April 2020.

Bullough Jr, R. V. (2005). Being and becoming a mentor: School-based teacher educators and teacher educator identity. Teaching and teacher education, 21(2), 143-155.

Cansoy, R. (2017). Teachers' Professional Development: The Case of WhatsApp. Journal of Education and Learning, 6(4), 285-293.

Available from: https://files.eric.ed.gov/fulltext/EJ1151679.pdf. Accessed 2 April 2020.

Cawyer, C. S., \& Friedrich, G. W. (1998). Organization socialization: Processes for new communication faculty. Communication Education, 47, 234-245

Church, K., \& De Oliveira, R. (2013, August). What's up with whatsapp?: comparing mobile instant messaging behaviors with traditional SMS. In Proceedings of the 15th international conference on Human-computer interaction with mobile devices and services (pp. 352-361). ACM.

Crescente, M. L., \& Lee, D. (2011). Critical issues of m-learning: design models, adoption processes, and future trends. Journal of the Chinese institute of industrial engineers, 28(2), 111-123. 
Creswell, J. W. (2002). Educational research: Planning, conducting, and evaluating quantitative (p. 676). Upper Saddle River, NJ: Prentice Hall.

Creswell, J. W., \& Creswell, J. D. (2017). Research design: Qualitative, quantitative, and mixed methods approaches. Sage publications.

Daloz, L.A. (1986). Effective Teaching and Mentoring. San Francisco, CA: Jossey-Bass.

Darwin, A. \& Palmer, E. (2009). Mentoring circles in higher education. Higher Education Research \& Development, 28(2):125-126. Available from: http://athleticmentoring.com/wpcontent/uploads/2010/08/Mentoring-Circles-in-Higher-Education-Study.pdf

27 January 2020.

Davies, M.B. (2007). Doing a Successful Research Project: Using Qualitative or Quantitative Methods. New York: Palgrave Macmillan.

Daresh, J. C. (1995). Research base on mentoring for educational leaders: What do we know?. Journal of Educational Administration.

Eraut, M. (2002). Conceptual Analysis and Research Questions: Do the Concepts of" Learning Community" and" Community of Practice" Provide Added Value?

Fairbanks, C. M., Freedman, D., \& Kahn, C. (2000). The role of effective mentors in learning to teach. Journal of Teacher Education, 51(2), 102-112.

Feldman, D. H. (2000). Forward. In V. John-Steiner, Creative collaboration (pp. ix-xiii). New York: Oxford University Press. 
Farnsworth, V., Kleanthous, I., \& Wenger-Trayner, E. (2016). Communities of practice as a social theory of learning: A conversation with Etienne Wenger. British journal of educational studies, 64(2), 139-160.

Gold, Y. (1996). Beginning teacher support: Attrition, mentoring, and induction. Handbook of research on teacher education, 2, 548-594.

Gourlay, L. (2011). New lecturers and the myth of 'communities of practice'. Studies in continuing education, 33(1), 67-77.

Guilfoyle, K., Hamilton, M. L., Pinnegar, S., \& Placier, M. (1995). Becoming teachers of teachers: The paths of four beginners. Teachers who teach teachers: Reflections on teacher education, 35-55.

Gülbahar, Y., \& Center, D. E. (2014). Current state of usage of social media for education: Case of Turkey. Journal of Social Media Studies, 1(1), 53-69.

Hedding, D. W., Greve, M., Breetzke, G. D., Nel, W., \& Van Vuuren, B. J. (2020). COVID19 and the academe in South Africa: Not business as usual. South African Journal of Science, 116(7-8), 1-3.

Hildreth, P. M., \& Kimble, C. (2002). The duality of knowledge. Information research, 8(1).

Hobson, A. J., Ashby, P., Malderez, A., \& Tomlinson, P. D. (2009). Mentoring beginning teachers: What we know and what we don't. Teaching and teacher education, 25(1), 207-216.

Holliday, A. (2007). Doing \& writing qualitative research. Sage. 
Hodkinson, H., \& Hodkinson, P. (2004). Rethinking the concept of community of practice in relation to schoolteachers' workplace learning. International journal of training and development, $8(1), 21-31$.

Hodkinson, P., \& Hodkinson, H. (2003). Individuals, communities of practice and the policy context: School teachers' learning in their workplace. Studies in continuing education, 25(1), 3-21.

Hodkinson, S., \& Taylor, A. (2002). Initiation rites: The case of new university lecturers. Innovations in Education and Teaching International, 39(4), 256-264.

Jennings, C. \& Wargnier, J. (2011). Effective Learning with 70: 20: 10. The New Frontier for the Extended Enterprise. Cross Knowledge. Available: https://alberonpartners.com/wpcontent/uploads/2019/09/Alberon_Wargnier_2011-70-20-10_vEN.pdf

Jokisalo, E., \& Riu, A. (2009). Informal learning in the era of Web 2.0. eLearning Papers, (14), 5.

Kajs, L. T., R. Alaniz, E. Willman, J. N. Maier, P. E. Brott, and D. M. Gomez. "Looking at the process of mentoring for beginning teachers." Retrieved November 6 (2001): 2003.

Knowles, J. G., \& Cole, A. L. (1994). We're just like the beginning teachers we study: Letters and reflections on our first year as beginning professors. Curriculum Inquiry, 24(1), 27-52.

Kram, K. E. (1983). Phases of the mentor relationship. Academy of Management journal, 26(4), 608-625.

Kram, K. E. (1988). Mentoring at work: Developmental relationships in organizational life. University Press of America. 
Kram, K. E., \& Isabella, L. A. (1985). Mentoring alternatives: The role of peer relationships in career development. Academy of management Journal, 28(1), 110-132.

Lambson, D. (2010). Novice teachers learning through participation in a teacher study group. Teaching and Teacher Education, 26(8), 1660-1668.

Lave, J., \& Wenger, E. (1991). Situated learning: Legitimate peripheral participation. Cambridge university press.

Levinson, D. J., Darrow, C. N., Klein, E. B., Levinson, M. H., \& McKee, B. (1978). The Seasons of a Man's Life. New York, Ballantine.

Lindgren, U. (2005). Experiences of beginning teachers in a school- based mentoring program in Sweden. Educational studies, 31(3), 251-263.

Lucas, C., \& Murry, J. W. (2016). New faculty: A practical guide for academic beginners. Springer.

Martinez, M. (2013). Adapting for a personalized learning experience. In Reshaping Learning (pp. 139-174). Springer, Berlin, Heidelberg.

Merriam, S. B. (2002). Introduction to qualitative research. Qualitative research in practice: Examples for discussion and analysis, 1(1), 1-17.

Mullen, C. A. (2016). Alternative mentoring types. Kappa Delta Pi Record, 52(3), 132-136. 
Nocco, M. A., McGill, B. M., MacKenzie, C. M., Tonietto, R. K., Dudney, J., Bletz, M. C., ... \& Kuebbing, S. E. (2021). Mentorship, equity, and research productivity: lessons from a pandemic. Biological Conservation, 255, 108966.

Alhija, F. N. A., \& Fresko, B. (2010). Socialization of new teachers: Does induction matter?. Teaching and teacher education, 26(8), 1592-1597.

Olsen, D. (1993). Work satisfaction and stress in the first and third year of academic appointment. The Journal of Higher Education, 64(4), 453-471.

Paris, S. G., \& Paris, A. H. (2001). Classroom applications of research on self-regulated learning. Educational psychologist, 36(2), 89-101.

Penner, R. (2001). Mentoring in higher education. DIRECTION-FRESNO-, 30(1), 45-52.

Saroyan, A. \& Trigwell, K. (2015). Higher education teachers' professional learning: Process and outcome. Studies in Educational Evaluation, 46, 92-101.

Savage, H. E., Karp, R. S., \& Logue, R. (2004). Faculty mentorship at colleges and universities. College teaching, 52(1), 21-24.

Schrodt, P., Cawyer, C. S., \& Sanders, R. (2003). An examination of academic mentoring behaviors and new faculty members' satisfaction with socialization and tenure and promotion processes. Communication Education, 52(1), 17-29.

Sherer, P. D., Shea, T. P. \& Kristensen, E. (2003). Online communities of practice: A catalyst for faculty development. Innovative Higher Education, 27, 183-194. 
Shpigelman, C. "Electronic mentoring and media." The handbook of youth mentoring (2014): $259-272$.

Single, P. B., \& Single, R. M. (2005). E- mentoring for social equity: review of research to inform program development. Mentoring \& Tutoring: Partnership in Learning, 13(2), 301320.

Single, P. B., \& Muller, C. B. (2001). When Email and Mentoring Unite: The Implementation of a Nationwide Electronic Mentoring Program--MentorNet, the National Electronic Industrial Mentoring Network for Women in Engineering and Science.

Smith, S. J., \& Israel, M. (2010). E-mentoring: Enhancing special education teacher induction. Journal of Special Education Leadership. 23(1), 30-40.

Sorcinelli, M. D., \& Yun, J. (2007). From mentor to mentoring networks: Mentoring in the new academy. Change: The Magazine of Higher Learning, 39(6), 58-61.

Susilo, A. (2014). Using Facebook and WhatsApp to leverage learner participation and transform pedagogy at the Open University of Indonesia. Jurnal Pendidikan Terbuka Dan Jarak Jauh, 15(2), 63-80.

Trowler, P., \& Knight, P. T. (2000). Coming to know in higher education: Theorising faculty entry to new work contexts. Higher education research \& development, 19(1), 27-42.

Ujakpa, M. M., Heukelman, D., Lazarus, V. K., Neiss, P., \& Rukanda, G. D. (2018, May). Using WhatsApp to support communication in teaching and learning. In 2018 IST-Africa Week Conference (IST-Africa) (pp. Page-1). IEEE. 
Veenman, S. (1984)."Perceived problems of beginning teachers." Review of educational research 54, no. 2, 143-178.

Vygotsky, L. (1978). "Interaction between learning and development." Readings on the development of children 23 , no. 3, 34-41.

Warhurst, R. P. (2008). 'Cigars on the flight- deck': new lecturers' participatory learning within workplace communities of practice. Studies in higher education, 33(4), 453-467.

Weimer, M. (2016). What it means to be a self-regulated learner.

Wenger, E. (1998). Communities of practice: Learning as a social system. Systems thinker, 9(5), 2-3.

Yavuz, F. (2016). Do smartphones spur or deter learning: A WhatsApp case study. International Journal of Educational Sciences, 15(3), 408-415.

Zey, M. G. (1991). The mentor connection: Strategic alliances in corporate life. Transaction Publishers.

Zimmerman, B. J. (2002). Becoming a self-regulated learner: An overview. Theory into practice, 41(2), 64-70. 